\title{
Um grito no escuro: o resgate da cultura inca em dias de globalização
}

\author{
Angela Zatta
}

Resumo: As origens da civilização inca se traduzem em lendas passadas através das gerações, das quais não se sabe o que é verdadeiro ou o que foi modificado pelos interesses coloniais. O que se sabe, de fato, é que os colonizadores buscaram fazer relações com o que havia na América e na Europa de forma que reduziram uma cultura complexa para uma categoria de inferior. Atualmente, a dificuldade de se conhecer a cultura inca como defendem seus descendentes está em identificar os mitos da conquista e inserir no cenário global hegemônico uma visão nova. Este artigo busca inserir novas idéias sobre a religiosidade andina, além de tratar dos mitos sobre a origem dos incas, das comparações com a civilização européia e tece uma critica do processo de globalização opressivo, que impossibilita o surgimento de novas teorias sobre a civilização inca.

Palavras-chave: Cultura inca, mitos, globalização.

Abstract: The origins of the Inca civilization are reflected in legends and stories passed down through the generations, of which no one knows what is true and what was modified by colonial interests. What is known, in fact, did the colonists to make connections with that they had in America and Europe so that a complex culture was reduced to a lower category. Currently, the difficult of knowing the Inca culture as defend their descendants is to identify the myths of conquest and in the global hegemonic insert new vision. This article aims to introduce new ideas about Inca's religion, besides dealing with the myths about the origin of the Icans,

\footnotetext{
* Graduanda em História, Universidade Federal do Paraná.
} 
of comparisons with European civilization and a critique of oppressive globalization process, which hinders the emergence of new theories about the civilization.

Keywords: Inca culture, myths, globalization

Pensar na cultura inca, como qualquer outro povo da América pré-colombiana, é pensar fragmentado. Nunca saberemos qual o verdadeiro significado das Linhas de Nazca ou entenderemos porque os incas deixaram a cidade de Machu Picchu inacabada. Quem se dispõe a estudar essas culturas, tem o passado como seu tirano, que o proíbe de conhecer a fundo já que não restaram evidencias que provem muitas das teorias atuais. "Em virtude dessa lacuna, toda uma parte de nossa história necessariamente incide sobre o aspecto, um pouco exangue, de um mundo sem indivíduos." ${ }^{1}$ Por mais frustrante que seja para nós, que nos dispomos a conhecer essas culturas, chega um momento em que é preciso resignar-se e admitir "não sei, não posso saber", afinal, o mundo em que vivemos, bem como o que estudamos, já está muitíssimo mudado.

É impossível não ver as influências de todo processo exploratório que aconteceu na América, desde a chegada dos Europeus até os dias atuais. A globalização como “o mundo visto como um conjunto único de atividades interconectadas que não são estorvadas pelas fronteiras locais, provocou um profundo impacto

\footnotetext{
${ }^{1}$ BLOCH, M. Apologia da história, p. 76.
} 
político e cultural, sobretudo na sua forma atualmente dominante de um mercado livre e sem controles." ${ }^{2}$, se apresenta tirana sobre a população local. O globalismo localizado, ou seja, o impacto das práticas transnacionais (como o turismo) sobre o contexto social peruano deixa o país dividido em duas grandes metades; a porção turística, rica e bem preservada, e a população nativa, pobre e oprimida.

Este artigo visa discutir a influencia da colonização e da catequização dos nativos na compreensão da cultura incaica e até que ponto as comparações feitas pelos colonizadores com a sua própria cultura é verdadeira. Trata também de analisar o que dizem alguns estudiosos peruanos sobre sua cultura ancestral, bem como os impactos do processo de globalização sobre o resgate cultural do povo andino.

\section{Os mitos}

O mundo inca ainda é envolto em mitos e lendas. A ocupação espanhola, como qualquer outra forma de dominação, não deu chance aos nativos de se expressarem livremente, de modo que as suas origens genealógicas provem de crônicas que chegaram até nós por meio dos próprios espanhóis ou ainda por indígenas ladinos. Assim, não é possível a qualquer historiador, chegar a origem pura da genealogia inca, uma vez que não sabemos até que ponto os colonizadores distorceram o relato pré-hispânico e muito menos, se

\footnotetext{
${ }^{2}$ HOBSBAWM, E. Globalização, democracia e terrorismo, p. 10.
} 
esses mitos correspondem de fato as reinterpretações dos nativos. Além disso, quando se trata das civilizações da América précolombiana, não se pode pensar a história do modo tradicional. "No caso completamente novo para nós de uma História sem arquivos, sem documentos escritos, apenas existe uma tradição verbal, que aparece ao mesmo tempo como História". ${ }^{3}$

As relações entre mito e história apresentam muitos problemas aos historiadores e antropólogos. Em primeira instancia, porque ao recolher os mitos, muitos deles nos chegam como uma colcha de retalhos permeada de histórias que são, a primeira vista, desconexas. Mas há também o extremo oposto; historias mitológicas extremamente coerentes, as quais se dividem em capítulos e seguem uma a outra em ordem lógica e organizada.

Um segundo problema está na forma como os mitos são recolhidos. Por volta do fim do século XIX e inicio do XX, este tipo de material era trabalho dos antropólogos, isto é, pessoas exteriores àquela realidade local e teoricamente neutras. Em muitos casos, como é o exemplo canadense, a colaboração dos nativos foi essencial, uma vez foi lhes dado a chance de contar suas próprias histórias e exaltar os feitos de seus antepassados. Entretanto, no Peru, o sistema de colonização adotado séculos antes pelos espanhóis, que não levava em conta as características culturais, bem como a catequização dos nativos, deixou duvidas quanto a originalidade dos mitos.

${ }^{3}$ LEVI-STRAUSS, Claude. Mito e Significado, p. 56. 


\section{As origens}

Garcilaso de La Vega relata detalhadamente "A origem dos Incas, Reis do Peru" "em sua obra Comentarios Reales. Segundo ele, um grande dilúvio que matou quase todos os seres humanos exceto alguns que se esconderam em cavernas e que foram responsáveis pelo posterior repovoamento do território. Entretanto, estes homens viviam em desordem de modo que o Deus Sol se apiedou dos mesmos e colocou seus filhos no Lago Titicaca para que reunisse o povo, o mantivesse em ordem e o ensinasse a cultivar a terra, colher os frutos, além de ensiná-los a viver como homens em matéria de razão e urbanidade. Os filhos do Deus Sol tinham uma varinha de ouro e deveriam encontrar um local onde ela afundasse na terra com apenas um golpe e ali fundar um povoado. Isso aconteceu em Cuzco, que no idioma quéchua significa umbigo.

Outras versões apresentam grupos de três ou quatro casais, por vezes tratados como irmãos, que habitavam cavernas $\mathrm{e}$ ensinaram a ordem aos demais antes de fundarem a cidade de Cuzco. É possível que a versão mítica que trata dos casais como irmãos se encaixe na ignorância espanhola em relação aos muitos aspectos da língua nativa.

Por ejemplo, se dice que los indígenas eran incestuosos y que el mismo Rey se casaba con su propia hermana, esta mala interpretación se debe a que en el Runa Simi no existe la

${ }^{4}$ LA VEGA, Garcilaso. El origen de los Incas Reyes Del Peru. In: Comentarios Reales, p 36-38. 
palabra amigo, las personas se vinculaban y aún lo siguen haciendo de la siguiente manera:

- un varón a otro varón le llama wayqey, es dicir, hermano.

- un varón a una mujer le llama panay, es dicir, hermana.

- una mujer a otra mujer le llama ñañay, es dicir, hermana.

- una mujer a un varón le llama turay, es dicir, hermano. ${ }^{5}$

Há também quem defenda que os povos da América sejam descendentes do patriarca bíblico Ofir (daí a denominação ofiritas). Conta o primeiro dos Livros dos Reis (1 Reis 10-11), o Rei Salomão era também um comerciante e apreciava, especialmente, artigos de luxo. Diz-se que Hiram enviou alguns servos marinheiros, familiarizados e conhecedores do mar, para junto dos navios com os servos de Salomão. Eles chegaram a Ofir e trouxeram quatorze mil quilos de ouro, os quais foram entregues ao Rei, mas não foi somente isto. A frota de Hiram trouxe também uma grande quantidade de madeira de sândalo e pedras preciosas. Talvez, a quantidade de ouro e pedras preciosas encontradas na América tenha feito os colonizadores repensarem a história bíblica, entretanto, os indícios não são suficientes para estabelecer qualquer relação entre as terras de Ofir e o Peru.

\footnotetext{
${ }^{5}$ MACHICADO FIGUEROA, Juan C., Cuando las Piedras Hablan: arquitectura inka y espiritualidad en los Andes, p. 86.
} 
É possível perceber que existe um grande apelo à catequização nestes discursos. Acidentais ou não, fazem refletir sobre a semelhança desastres bíblicos como o dilúvio, ou sobre uma possível (embora remota) relação entre o Peru e o Velho Mundo séculos antes de Cristo. Mesmo no discurso de La Vega, natural do Peru e considerado "Príncipe dos escritores do Novo Mundo" é apresentada a idéia curiosa de uma civilização inca que possuía uma crença a qual lhe permitiria, mais tarde, crer no verdadeiro e único deus.

Viviendo o muriendo aquellas gentes de la manera que hemos visto, permitió Dios nuestro Señor que dellos mismos saliese un lucero de alba, que en aquellas escurísimas tinieblas les diese alguna noticia de la ley natural, y de la urbanidad y respetos que los hombre debían tenerse unos a otros, y que los descendientes de aquél, procediendo de bien en mejor, cultivasen aquellas fieras y las convirtiesen en hombre, haciéndoles capaces de razón y de cualquiera buena doctrina, para que cuando ese mismo Dios, sol de justicia, tuviese por bien de enviar la luz de sus divinos rayos a aquellos idólatras, los hallase no tan salvajes, sino más dóciles para recibir la fe católica, y la enseñanza y doctrina de nuestra Santa Madre Iglesia Romana, como después acá la han recibido, 
según se verá lo uno y lo otro en el discurso desta historia. $^{6}$

\section{A comparação}

Esses discursos, brevemente apresentados, refletem a luta de alteridade, uma antiga conhecida do mundo Ocidental. Desde os relatos de Heródoto, a alteridade vem como um modo de estabelecer um parâmetro entre aquilo que é conhecido e o novo, um modo de identificação do "outro" como ser antagônico a partir de elementos conhecidos. Mas para estabelecer um "outro" o historiador dispõe de outra forma de discurso na retórica da alteridade; a comparação, que é "uma maneira de reunir o mundo que se conta e o mundo em que se conta, passando de um ao outro."7

Muitos viajantes e cronistas espanhóis desenvolveram seus relatos baseados na comparação. Era importante que eles conseguissem explicar o que encontravam na America de um modo que quem os lesse do outro lado do Mar Tenebroso pudesse compreender o que havia por aqui. Assim, alguns cronistas entenderam as representações simbólicas da terra sob a forma de mulheres grávidas ou robustas, que simbolizavam a fertilidade e a natureza, como representações de uma possível Vênus Andina. Acontece que os colonizadores, visto que se depararam com uma

\footnotetext{
${ }^{6}$ LA VEGA, Garcilaso, op. cit., p. 36.

${ }^{7}$ HARTOG, Fraçois. O Espelho de Herodoto: ensaio sobre a representação do outro, p. 240.
} 
cultura completamente diferente, não compreenderam a relação estabelecida pelos incas entre a fertilidade da terra com a da mulher, ou seja, a mulher como Pachamama.

Outra comparação gritante com a cultura ocidental mediterrânica se dá com relação a espiritualidade andina. Os espanhóis observaram que os Incas faziam oferendas a diversos elementos da natureza e pensaram se tratar de uma cultura politeísta, a qual estabeleceram semelhança ao panteão Grego

concediéndole a la espiritualidad Andina un aire del Olimpo, donde el sol desempeñaba el rol de dios principal, la luna como su esposa, las estrellas como hijas y semidioses o dioses terrenales eran el agua, las montañas, la tierra, el cóndor, el jaguar o puma y otros animales. ${ }^{8}$

Da mesma forma, os sacerdotes católicos tomaram por demônios os guardiões espirituais que viviam embaixo da terra segundo a cultura inca. Não se devia esperar nada de diferente uma vez que a fé católica gira em torno da tentativa de evitar ser mandado ao inferno quando chegar a hora do Juízo. Para uma cultura que acabava de entrar na Idade Moderna, que vinha de uma Europa em que fervilhavam movimentos protestantes e cuja religiosidade, especialmente no caso espanhol (que continuou fiel ao poder pontífice), fora um dos impulsos para se lançar ao mar na busca de novos povos, encontrar um povo que cultuava tais espécies de guardiães espirituais era como se deparar com adoradores do

\footnotetext{
${ }^{8}$ MACHICADO FIGUEROA, Juan C., op. cit., p. 87.
} 
demônio. Tal interpretação fez com que ainda hoje alguns guardiões representados em certas zonas mineradoras bolivianas sob o nome de El Tío tenham a forma de um diabo.

Além disso, para a fúria dos peruanos, a monumental arquitetura dos edifícios, a extensão e manutenção dos caminhos, fez brotar espontaneamente a comparação com "obra dos romanos".

\section{Os novos mitos}

Restall chamou atenção para os mitos criados pelos cronistas que relatam a conquista da America. Segundo ele, os colonizadores não eram uma minoria capaz de subjugar milhares de nativos que conheciam o terreno. Eram, em sua maioria, homens despreparados, mal armados e famintos que faziam aliança com nativos aliados para sobreviver para a próxima batalha. Ocorre um exagero proposital nos relatos para tentar conseguir do Rei algum tipo de "encomienda" ou recompensa por seus serviços prestados pela Coroa.

Começam a surgir os mitos da conquista. Muito difundidos por todo ocidente, eles mostram um grupo de notáveis espanhóis, bem treinados e armados, que foram capazes de subjugar milhares de nativos e derrotar alguns dos impérios mais surpreendentes que o mundo já vira. Essas teorias, que hoje são tidas como mitos, foram confirmadas até a exaustão por religiosos, cronistas e biógrafos da época. Era uma forma de exaltar a supremacia da Coroa Real Espanhola sobre as demais monarquias que floresciam na Europa.

A motivação para descrever a conquista do Tahuantinsuyu foi essencialmente o desejo de eternizar as memórias idealizadas dessas 
aventuras espanholas. Hernando Pizarro, Cristobal de Mena, Francisco Xerez, Pero Sancho de Hoz, Miguel de Estete, Juan Ruiz de Acre, Diego de Trujillo e Pedro Pizarro foram os pioneiros nessa empreitada. Embora a literatura, e mesmo a historiografia, os considere Cronistas das Índias, os textos que produziram foram "relaciones", ou seja, um testemunho direto de participantes da conquista. A maioria desses autores escreveu imediatamente após a ação, no repouso do acampamento, o que permitiu que alguns textos pudessem transmitir ao leitor o calor da batalha ou a tensão das negociações a partir da riqueza de detalhes que contém.

Tais relatos certamente são ótimas fontes para compreendermos o que sentiram, pensaram e viram estes homens que acompanharam lideres como Pizarro. Alguns soldados coletaram dados para seus textos com os quipucamayoc, homens que conservavam a história incaica através do quipu, um conjunto de cordões coloridos com nós, onde era guardada a memória do povo e se contabilizava a produção econômica. Outros puderam recolher informações junto aos chefes locais em todo território. Este material originou as Relaciones Geográficas de Indias.

A ambição de enriquecer com o comercio de especiarias, bem como com ouro e prata levou muitos aventureiros a se lançarem ao mar. Entretanto, antes da sua chegada na América, os sacerdotes e lideres espirituais incas já sabiam, a partir da observação das entranhas de animais sacrificados, que coisas terríveis estavam por vir. Corriam boatos da existência de monstros marinhos e homens com barbas que andavam no mar em grandes casas. Houve também 
quem afirmasse que eram viracochas (deuses), estes tais homens de barbas negras ou ruivas, de belos trajes, que se locomoviam em grandes animais que possuíam pés de prata. Homens, deuses ou monstros, os homens que chegaram foram os responsáveis pelo massacre de grande parte da população andina.

\section{O conflito}

O encontro, diz-se, começou com uma tentativa de reciprocidade entre Pizarro e Atahualpa, em 1532. Segundo Xerez, a guerra só teve inicio quando Atahualpa jogou a Bíblia Sagrada no chão e, assim, ofendeu os cristãos. Pizarro então ordenou o ataque. $\mathrm{O}$ líder inca foi prontamente capturado e o alvoroço se estabeleceu; muitos índios correram para todos os lados, desesperados, buscando fugir dos tiros e das patas dos cavalos, mas outros ficaram paralisados de terror. A grande maioria daqueles que se encontravam na praça de Cajamarca, morreu ali mesmo. Pizarro detinha Atahualpa como prisioneiro e exigiu um imensurável resgate, mas mesmo depois de receber todo montante de ouro e prata exigido, condenou-o a morte. $\mathrm{O}$ Inca tentou negociar sua vida, argumentando que Pizarro prometera receber o resgate, libertar-lo e sair de seus domínios, mas visto que não o faria e ainda o sentenciaria a morte teria grandes problemas. Pediu que o capitão o enviasse a Espanha, falar com o Rei e oferecer a ele grande quantidade de ouro e prata, assegurando-o que caso desse cabo de sua vida, seus súditos teriam um novo Rei que mataria todos os espanhóis. Mantê-lo com vida era, portanto, a garantia de que haveria paz no país. 
Seus pedidos surtiram pouco efeito. Atahualpa foi retirado da prisão e levado, ao som de trombetas, para a praça onde foi amarrado a um pau. Ao longo do caminho, um religioso ia com ele para consolá-lo e predicar-lhe a fé cristã, por meio de um interprete. Estava condenado a morrer na fogueira, mas nos últimos instantes concordou em ser batizado e teve a graça de morrer garroteado. Cumprida a sentença, lhe atiraram fogo para que suas roupas e parte de sua carne queimasse. Pizarro e seus companheiros assistiram ao enterro, que teve direito a cruz e demais aparatos religiosos cristãos, sendo que por fim seu corpo foi enterrado em uma igreja, como um verdadeiro espanhol cristão.

$\mathrm{O}$ assassinato de Atahualpa representou muito mais do que apenas um episodio trágico na vida andina. Este fato, bem como toda conquista espanhola, mostra como a ignorância, consciente ou não, da forma de vida do "outro" pode gerar um desencontro cultural cujas conseqüências sejam realmente desastrosas. Entretanto, cabe lembrar que os espanhóis sabiam como agir com os nativos. Eles estabeleceram, desde o principio, um sistema de reciprocidade, de troca de presentes e mercadorias, que não deu motivos aos índios de terem cautela para com os espanhóis. Desta forma, o fator surpresa do ataque em Cajamarca foi essencial.

É sabido que os incas desconheciam lutas com cavalos, tiros e demais coisas que lhes eram aterrorizantes, mas somente estes fatores não bastam para compreender como 168 espanhóis foram capazes de combater e derrotar milhares de nativos. Cabe aqui lembrar que para eles, Atahualpa não era somente um governante; ele era o Inca, tido 
como uma divindade e responsável por todos os atos e aspirações dos demais. Os milhares de índios que assistiram ao aprisionamento de seu líder ficaram absolutamente perdidos, imersos em terror e desespero, já que não tinham por habito tomar decisões individuais nesses casos. A verticalidade do poder era um importante fator de reação diante do perigo.

Estratégicos ou sortudos, os espanhóis tinham pela frente uma tarefa muito mais complexa; governar o Império Inca.

\section{A voz dos descendentes}

Estando o Peru na posição de colônia, não podemos esperar que hajam relatos anteriores à sua independência que sejam capazes defender a cultura inca em sua essência pura. Entretanto, este tipo de analise não pode se basear apenas na dicotomia entre vencedores e vencidos. Como defende Said $^{9}$, ao discorrer sobre o desempenho retórico de Arthur J. Balfour em um discurso à Câmara dos Comuns, aquele que dispõe da palavra (no caso da colônia inglesa no Egito) pode representar uma variada gama de personagens. Neste caso, o cronista, ou o religioso que escreve sobre a nova terra pode falar em nome da Coroa, como o que há de melhor na história da nação, e ao

\footnotetext{
${ }^{9}$ Esta analise do texto de Said é pertinente neste caso porque, embora o Peru se localize na porção ocidental do globo, os descendentes incas não se consideram realmente ocidentais. Entretanto, cabe salientar que esta é uma analise feita pelo autor sobre o discurso de Arthur J. Balfour em 13 de junho de 1910, referente aos problemas que a corte inglesa enfrentava no Egito, e não a opinião do autor sobre a colonização inglesa.
} 
mesmo tempo pode representar todo o mundo civilizado, ou todo o Ocidente e os ocidentais. Said ainda defende que se quem fala não o faz diretamente pelos nativos é pelo motivo mais óbvio, eles tem outra língua! Entretanto, o cronista sabe o que eles sentem porque conhece o que há para conhecer da sua história e de suas expectativas. E ainda, caso fosse perguntado aos nativos o que eles tem a dizer, certamente eles confirmariam tudo o que já foi dito sobre como sua raça foi subjugada, dominada por outra raça que lhe é superior, que o conhece e sabe o que é bom para eles, talvez até o saiba melhor que eles próprios poderiam saber. "Os seus grandes momentos estavam no passado; são úteis no mundo moderno apenas porque os novos impérios poderosos efetivamente os tiraram da desgraça de seu declínio e transformaram-nos em residentes de colônias produtivas." ${ }^{10}$

Mesmo quando o Peru conseguiu sua independência, a elite peruana ainda se mostrava fortemente monarquista, de modo que somente muitos anos mais tarde foi possível falar abertamente sobre a cultura inca, sem enfrentar tantas barreiras políticas. Hoje em dia, historiadores e antropólogos, peruanos ou não, batalham dia após dia para tentar resgatar esta cultura afogada por idéias errôneas que atravessaram os séculos.

Um forte exemplo é o antropólogo Juan Carlos Machicado Figueroa que defende uma linha teórica em muito divergente da tradicional, que chegou até nós pelos conquistadores espanhóis.

${ }^{10}$ SAID, E. W. Orientalismo: o oriente como invenção do ocidente, p. 66. 
Segundo ele, a civilização inca era monoteísta e seus wakas, ou entidades espirituais, não eram semideuses como se supunha. Além disso, Juan defende que a cultura inca não tinha o sol como divindade e baseia sua argumentação nos achados arqueológicos e nas obras de arte do período inca.

Machicado Figueroa diz que a representação religiosa mais importante do Qorikancha, o Templo do Sol, tem forma humana e quando era representado de forma circular, possuía feições humanas. $\mathrm{O}$ que se conhece de mais próximo desta imagem é a Placa de Echenique, hoje escudo da cidade de Cusco. A imagem humana é semelhante às estatuas que tem formas humano-felino-ofidias, estilizadas de diversas maneiras ao longo de cada período histórico. $\mathrm{O}$ autor defende que nenhuma escultura ou representação solar foi encontrada nas casas ou templos incas, ao passo que esta representação aparece diversas vezes, em muitos momentos da história, o que leva a crer que a imagem seja realmente uma divindade importantíssima, já que os incas se caracterizam por ser um povo altamente espiritual não é possível esperar que tenham se privado de representar sua maior divindade.

O discurso de Machicado Figueroa é permeado pela mágoa da colonização. Não estabelecendo o Peru no bloco Ocidental do globo, o antropólogo trata a própria cultura com paixão e tenta alcançar as verdades perdidas há muitos séculos atrás. Embora unilateral e radical, talvez seja de discursos como estes que precisamos hoje para que seja possível chegar num meio termo sem que nenhuma das partes saia demasiado ofendida. 
Figueroa defende que a cultura inca deve ser resgatada e que pode haver uma comunhão entre as tradições incaicas com o mundo capitalista globalizado. Talvez seja possível, de fato. Mas o cenário global pede a todo instante uma série de mudanças no individuo e, conseqüentemente, na sociedade, que não era previsto na cultura inca. Além disso, os estilos de vida e comercio atuais estão diametralmente opostos à espiritualidade e comunhão andina do dia a dia. Quem sabe o mundo ainda não esteja preparado para viver esta filosofia andina de comunhão com a natureza, por isso é preciso desmistificar e exaltar este povo tão peculiar, antes que seu legado chegue ao fim e, especialmente, antes que seus próprios descendentes percam o encanto pelo que é seu de fato e direito.

\section{Considerações finais}

Como dito anteriormente, tratar da cultura inca é mergulhar em algumas incertezas. Não nos cabe julgar a colonização do século XVI, nem determinar que todos os historiadores estão errados ao afirmar que o deus dos Andes era o Sol. É preciso, antes de tudo, entender que existem muitas versões de uma mesma história e então buscar evidencias que comprovem ou refutem as teorias.

O Peru atual tem grande parte da economia girando em torno do turismo, de modo que sua cultura ancestral se transformou paulatinamente em um produto a ser consumido pela massa de turistas que vem e vão o ano todo. É possível encontrar xamãs turísticos e guias que se adaptaram a cada publico que visita o país. 
Mas é chegada a hora dos peruanos serem egoístas, contrahegemônicos, e deixarem de lado a projeção mundial que seus monumentos tomaram para conhecer realmente sua cultura. Somente com esse reconhecimento, de dentro para fora, será possível impedir que o conhecimento, desenvolvimento e a espiritualidade andina se percam, tornando-se mais um souvenir.

\section{Referências}

BLOCH, Marc. Apologia da História: ou o ofício do historiador. Rio de Janeiro: Jorge Zahar, 2001.

MACHICADO FIGUEROA, Juan Carlos. Cuando las Piedras Hablan:arquitectura inka y espiritualidad en los Andes. Inka 2000 Productions, 2002.

GARCILASO DE LA VEJA, Inca. Comentarios Reales, 1609.

HARTOG, François. O Espelho de Heródoto: um ensaio sobre a representação do outro. Belo Horizonte, UFMG, 1999.

HOBSBAWM, Eric. Globalização, democracia e terrorismo. São Paulo: Companhia das Letras, 2007.

LEVI-STRAUSS, Claude. Mito e Significado. Lisboa: Edições 70, s/d.

RESTALL, Matthew. Sete Mitos da Conquista Espanhola. Rio de Janeiro: Civilização Brasileira, 2006.

SAID, Edward W. Orientalismo: oriente como invenção do ocidente. São Paulo: Companhia das Letras, 2007. 